\title{
APLICAÇÃO DO PLANEJAMENTO ESTRATÉGICO SITUACIONAL EM ESFERA PÚBLICA: CONSTRUÇÃO DO PLANO OPERATIVO (PO) NA ASSISTENCIA FARMACÊUTICA MUNICIPAL
}

\author{
A. L. SILVA $^{1}$, M. APOLINÁRIO FILHO ${ }^{2}$, R. M. F. SILVA ${ }^{1}$, J. O. S. SILVA ${ }^{1}$ e T. B. \\ JERÔNIMO ${ }^{3}$
}

${ }^{1}$ Universidade Federal de Pernambuco, Departamento de Ciências Farmacêuticas
${ }^{2}$ Prefeitura Municipal de Ipojuca, Central de Abastecimento Farmacêutico (CAF)
${ }^{3}$ Universidade Federal de Pernambuco, Departamento de Ciências Administrativas.

E-mail para contato: andrea.luciana20@gmail.com

\begin{abstract}
RESUMO - A assistência farmacêutica (AF) nos municípios brasileiros tem enfrentado diversos problemas de gestão quanto à aquisição de medicamentos e produtos para saúde. A superação desses problemas pode ser realizada através da construção do Plano Operativo (PO), por meio dos pilares que sustentam o Planejamento Estratégico Situacional (PES). O objetivo deste trabalho foi apontar estratégias para a identificação e caracterização do problema mais relevante para a Assistência Farmacêutica municipal. Trata-se de um estudo de caráter descritivo e qualitativo, realizado no período de novembro de 2014 a março de 2015 com a participação dos profissionais farmacêuticos. Para o município em estudo, o plano contribuiu para o alcance de uma visão mais assertiva quanto à morosidade no processo de aquisição de medicamentos, a continuidade dos processos de trabalho, a qualidade da assistência prestada aos usuários do Sistema Único de Saúde (SUS) e na avaliação da gestão municipal.
\end{abstract}

Palavras-Chave: Planejamento Estratégico Situacional, Assistência Farmacêutica, Aquisição de Medicamentos.

ABSTRACT - Pharmaceutical assistance (PA) in Brazilian municipalities has faced several management problems regarding the acquisition of medicines and health products. The overcoming of these problems can be accomplished through the construction of the Operational Plan (OP) through the pillars that support the Strategic Situational Planning (SSP). The objective of this work was to identify strategies for the identification and characterization of the most relevant problem for the Municipal Pharmacy Assistance. It is a descriptive and qualitative study, carried out from November 2014 to March 2015 with the participation of pharmacists. For the municipality under study, the plan contributed to the achievement of a more assertive view on the length of the drug acquisition process, the continuity of work processes, the quality of care provided to users of the Unified Health System (SUS) and in the evaluation of municipal management.

Keywords: Strategic Planning Situational, Pharmaceutical Assistance, Acquisition of Medications. 


\section{INTRODUÇÃO}

INOVAÇÃO TERAPÊUTICA

A gestão do setor público se caracteriza, muitas vezes, pela falta de planejamento e pelo improviso na resolução de problemas (MATUS, 1993). Para problemas complexos de cunho administrativo, econômico e social, é necessário usar modelos adequados, capazes de espelhar essa complexidade. Como exemplo deste modelo, tem-se o Planejamento Estratégico Situacional (PES). Neste método, o futuro não é determinístico e a realidade deve ser contínua e sistematicamente acompanhada e revisada (SILVA et al., 2017).

Diante deste cenário, é oportuno e justificável o uso e implementação do PES na Assistência Farmacêutica (AF) em organizações públicas. A Assistência Farmacêutica (AF) apresenta-se como uma área estratégica para os sistemas de saúde na medida em que a aquisição do medicamento representa uma das principais ferramentas de intervenção sobre grande parte das doenças e agravos que acometem a população (ESPIRITO SANTO, 2007).

A descontinuidade nos processos de trabalho, o atraso no cronograma mensal de entrega dos medicamentos e insumos farmacêuticos e a interrupção das atividades logísticas (entradas, saídas e gerenciamento dos estoques), em decorrência da morosidade nos processos de compras, originou a necessidade de realizar o presente estudo. Desta maneira, este estudo tem por objetivo apontar estratégias para a identificação e caracterização do problema mais relevante, através da construção de um Plano Operativo (PO), a fim de resolver os problemas quanto à aquisição de medicamentos para a rede municipal de saúde em questão.

\section{MATERIAIS E MÉTODOS}

A pesquisa tem natureza qualitativa baseada nas experiências vivenciadas e no contexto dos acontecimentos, sendo a estratégia de pesquisa o estudo de caso desenvolvido entre novembro de 2014 e março de 2015 no município de Ipojuca - PE. A investigação desta pesquisa foi feita com a participação de 08 farmacêuticos lotados nos serviços de Urgência/ Emergência e Policlínicas de especialidades. Os instrumentos de coleta de dados foram: entrevistas e observação participante, durante a oficina de priorização dos problemas, e diário de campo. O PO foi desenvolvido seguindo a divisão dos momentos do PES: explicativo, normativo, estratégico e tático-operacional. Neste trabalho, foi abordado apenas o momento explicativo.

\section{RESULTADOS E DISCUSSÃO}

O foco escolhido para aplicação da ferramenta do Planejamento Estratégico Situacional (PES) foi a Assistência Farmacêutica Municipal. Durante a realização das oficinas do momento explicativo no período entre novembro de 2014 e março de 2015, foram discutidos e levantados os seguintes problemas: (1) ruptura de estoque; (2) Espaço físico inadequado das farmácias; (3) Infraestrutura; (4) Formação dos auxiliares de farmácia; (5) Dificuldades no processo licitatório; (6) Ausência de qualificação de fornecedores. Em seguida, foi realizada a priorização do problema, atribuindo pontuações de 1 até 4 conforme os critérios de magnitude, transcendência, vulnerabilidade, urgência e factibilidade (VEBER; LACERDA; CALVO, 2011). Ao final, foi selecionado o mais relevante para a população. 
Quadro 1: Priorização do Problema - Momento explicativo

\begin{tabular}{|c|c|c|c|c|c|c|}
\hline \multirow{2}{*}{ Problema } & Magnitude & Transcedência & Vulnerabilidade & Urgência & Factibilidade & \multirow{2}{*}{ Total } \\
\cline { 2 - 6 } & Tamanho & Interesse & Reversão & Espera & Recursos & \\
\hline 1 & 32 & 25 & 13 & 25 & 24 & 119 \\
\hline 2 & 22 & 17 & 22 & 16 & 19 & 96 \\
\hline 3 & 24 & 19 & 21 & 17 & 19 & 100 \\
\hline 4 & 24 & 15 & 18 & 19 & 16 & 92 \\
\hline 5 & 30 & 21 & 20 & 29 & 23 & 123 \\
\hline 6 & 25 & 16 & 17 & 22 & 22 & 102 \\
\hline
\end{tabular}

O problema priorizado após a somatória das pontuações atribuídas foi "Dificuldades no processo licitatório". Após a priorização do problema, foi escolhido o problema priorizado, e, concomitantemente sucederam-se as demais fases da pesquisa. A primeira ação foi à explicação do Diagrama de Causa e Efeito aos participantes da pesquisa. Desta forma, guiou a construção da imagem-objetivo para AF em estudo. Foi consenso entre os atores a definição de "Descritor" do problema como sendo uma evidência da situação abordada. Para o problema "Dificuldades no processo licitatório", os participantes da oficina apontaram os descritores: Elevado número de aquisições por dispensa de licitação; Finalização de processo licitatório após quase 12 meses da ocorrência do pregão presencial.

Figura 1: Espinha de Peixe - Momento explicativo

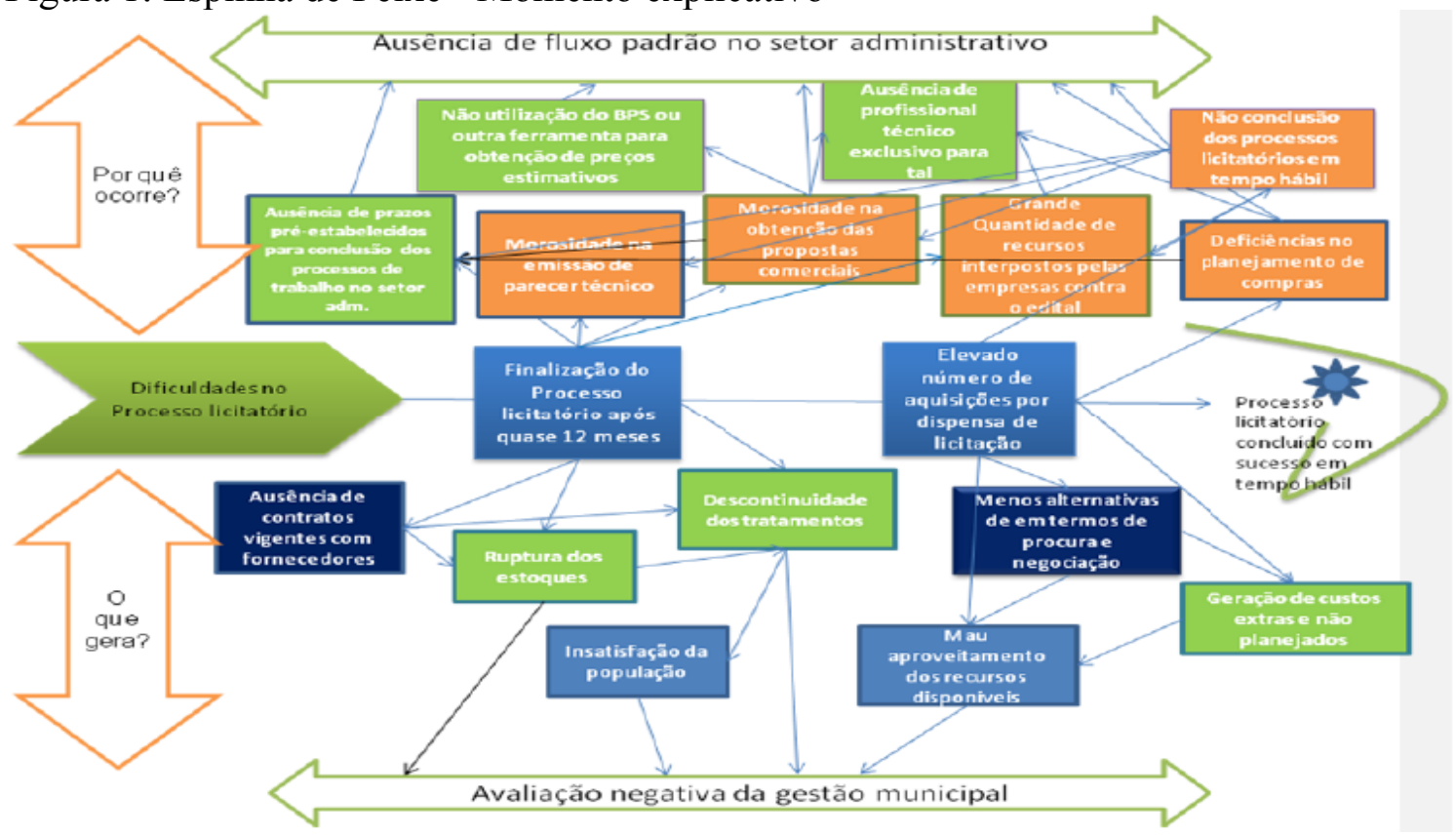

A Figura 1 traz as principais causas e consequências para o problema da dificuldade no processo licitatório. A problemática na estrutura organizacional do setor de compras ocasionada pelos motivos listados na espinha de peixe (Figura 1) tem provocado sérias consequências, que vão desde a geração de custos extras não planejados até a insatisfação da população atendida.

\section{CONCLUSÃO}

A principal contribuição do PES foi evidenciar a necessidade do diálogo, pois as propostas e ações planejadas dependem de articulações para serem colocadas em prática. 
Foi possível verificar que o Plano Operativo (PO) realizado através do Planejamento Estratégico Situacional (PES) na assistência farmacêutica, mostrou-se positivo para o enfrentamento do problema anteriormente priorizado, principalmente por envolver os profissionais farmacêuticos a vivenciarem a realidade da qual fazem parte, contribuindo para a superação das barreiras operacionais quanto à aquisição de medicamentos para a rede municipal de saúde.

A elaboração do PES mostrou-se factível, pois, conseguiu sensibilizar o gestor municipal a utilizar o banco de preço em saúde como estimativa de preço em seus processos licitatórios para a compra de medicamentos e produtos para a saúde, contribuindo desta forma para a continuidade nos processos de trabalho e a construção de uma imagem positiva para a gestão.

\section{REFERÊNCIAS}

BRASIL. Conselho Nacional de Secretários de Saúde. Nota Técnica 15/2014: Apresentação das dificuldades enfrentadas pelas Secretarias Estaduais de Saúde na aquisição de medicamentos. Brasília: CONASS, 2014.

ESPÍRITO SANTO (Estado). Decreto no 1956-R de 07 de novembro de 2007. Aprova a Política Farmacêutica do Estado do Espírito Santo e dá outras providências. Disponível em: HTTP://200.165.59.196/farmaciacidada/_midias/pdf/18349a6df551cc53.pdf. Acesso em 16 de agosto de 2015.

MATUS, C. Política, planejamento e governo. Brasília: Editora IPEA, 1993.

SILVA, J. O. S.; JERÔNIMO, T. B.; MELO, F. J. C.; AQUINO, J. T. Planejamento Estratégico: elaboração do plano operativo na central de abastecimento farmacêutico. RAHIS, v. 13, n. 4, 2017.

VEBER, A. P.; LACERDA, J.T.; CALVO, M.C.M. Planejamento em Saúde. Gestão da Assistência Farmacêutica. Florianópolis: UFSC, 2011. 